\title{
Fetal Kidney
}

National Cancer Institute

\section{Source}

National Cancer Institute. Fetal Kidney. NCI Thesaurus. Code C34168.

The development of the kidney after the eleventh week of gestation until the time of birth. 